\title{
Three User-Driven Innovation Methods for Co-creating Cloud Services
}

\author{
Ting-Ray Chang and Eija Kaasinen \\ VTT Technical Research Centre of Finland, \\ Tekniikankatu 1, P.O. Box 1300, \\ FI-33101 Tampere, Finland \\ \{ting-jui.chang, eija.kaasinen\}@vtt.fi
}

\begin{abstract}
The role of users in design is changing from one of passive research subjects to one of active co-designers. Users are the best experts of their everyday life experiences, making them great potential sources of innovation. User-driven innovation requires methods by which user ideas can be captured and worked on further with designers. In this paper, we describe our experiences of three different methods to co-create cloud services. Our aim was to innovate with users how open access to telecommunication data such as user location, user profile and usage logs could be utilised in cloud services. The user-driven innovation methods included focus group, crowdsourcing in an open web lab and face-to-face interaction in an open innovation showroom. We compare these three methods and identify the best usage possibilities for each. We propose guidance on selecting user-driven innovation methods based on the available resources and targeted results.
\end{abstract}

Keywords: User-Driven Innovation, Co-creation, Cloud Services, HCI research methods, Focus Group, Crowdsourcing, Open Web Lab (Owela), Open Innovation Showroom (Ihme).

\section{Introduction}

Today, human-centred design is an established practice for designing products and services so that the forthcoming users are represented in the design process. In a human-centred design process, user feedback is gathered throughout the iterative design process, and the design is refined accordingly. The process starts with identifying user needs by observing or interviewing users. In this phase, the decision to design a certain kind of product or service has already been made. To increase the user role in design and innovation, we should increasingly involve them in deciding what is needed and what kinds of products should be designed for them and with them. Kanstrup and Christiansen [1] describe this change as shifting the user role in design from a victim who needs support to a valuable source of inspiration. This change in the user role calls for user involvement in the innovation processes.

In user-driven innovation, users are no longer considered a reference group that sets the specifications for a system but a source of inspiration that can foster innovation [2]. User-driven design integrates user studies and idea generation [3]. A 
crucial factor for product and service development success is the performance in the early stages of the development process, that is a 'fuzzy front-end' when the targeted product or service is yet to be decided [4]. User involvement could be especially useful at this stage due to the high uncertainty and low formalization [5].

We have applied user-driven innovation to the case of future cloud services. Cloud computing refers to the paradigm shift from traditional installable applications to web-based software, where applications live on the Web as services. In cloud computing applications, hardware and system software are on remote data centres that can be located anywhere in the world [6]. In Cloud computing, resources can be purchased on demand from a virtually unlimited supply [7]. We have been studying a special case of cloud computing: Open Telco. Open Application Programming Interfaces (APIs) are a set of technologies that enable applications and services to interact with each other. This eases application design, as applications can utilise features and services provided by other service providers [8]. Open Telco is an open API framework for mobile networks. It gives external developers access to data and functionalities traditionally possessed by teleoperators. This enables open development of mash-up services that take advantage of network assets such as mobile payment capability, user profiles or location information [8].

In this paper, we describe and compare three approaches to user-driven innovation of Open Telco services. Our approaches were technology-driven rather than market pull, as we were dealing with radical improvements in functionality [9]. The userdriven design aim was to identify the meanings for the users of the various possible functionalities - the kinds of services that could be the forerunners of Open Telco. User-driven innovation activities were carried out using three methods. In focus group, users and designers met and ideated new services in a meeting room. In Open Web Lab, the ideation was taken to the web with social media. This made the ideation independent of time and place. The third study was carried out at an open innovation showroom in a real-world setting in which researchers and users interacted directly. The users could easily pop in when they had time, ideate with us, stay as long as they wanted and leave at their free will.

The paper is structured in the following way. Section 2 gives an overview of related research on user-driven innovation and co-creation. Section 3 describes the Open Telco case study. Section 4 describes how we applied the three user-driven innovation methods in practice and, finally, section 5 compares the methods and gives recommendations on how the methods can be applied.

\section{Related Work}

In marketing and human-computer interaction (HCI) research fields, the user role is changing from one of research subjects to one of co-creators. In marketing, one contributing factor has been the growing emphasis on services instead of products. A service provider has to establish, maintain and enhance the relationship with customers. This relationship-marketing approach emphasizes continuous interaction and co-creation with users [10]. User-driven design integrates user studies and idea generation and includes users as equal partners in the early phases of design [3]. In user-driven innovation, users are a source of inspiration that can foster innovation [2]. 
Participatory design focuses on designing social systems together with users and other stakeholders [11]. It has mainly been used to design work practices and work tools with different professionals. This is why participatory design is connected to a certain user community and usage context, whereas user-driven innovation may aim to innovate possible usages and usage contexts.

Hyvönen et al. [12] found direct contact between users and product developers to be an important element of user involvement. They emphasize the necessity of a common space where users and developers can meet. Sandström et al. [13] point out that functional elements of service experience are best met by services based on users' ideas. Ideas that improve the emotional elements of the service experience (like enjoyment and fun) can be difficult for users to generate spontaneously. This is why Sandström et al. recommend a combination of customer- and company-generated ideas for service innovation. In the case studies by Hyvönen et al. [12], focus groups that brought together users and developers turned out to be the most beneficial. The feedback from direct interaction was impressive and influencing.

The best known customer role in innovation is that of lead users introduced by von Hippel [14]. Lead users are characterized by their interest in the product, their frequent use of it or their activeness in information processing. Lead users have the ability to sense important market trends before the majority, which is why they may act as a 'needs-forecasting' laboratory. Alam [5] proposes that both lead users and ordinary users should be involved in the development process, as lead users are able to produce new ideas and their attractiveness can then be tested with ordinary users. An even more broadminded approach suggests that every user can offer something to the innovation process [15]. The only things that need to be determined are what kind of information is needed, what kinds of users or user groups are the best sources and what kind of interaction technique best enables the contribution.

In their study concerning open innovation communities such as CrowdSpirit and FellowForce, Antikainen et al. [16] differentiate between motivation to participate and motivation to collaborate. They identified, e.g., the following motivational factors for collaboration: interesting objectives, an open atmosphere, possibility to be influential, a sense of efficacy, having fun, a sense of community and rewards.

Design no longer just comes out of so-called 'black box' of designers' creative minds but involves different experts and users. Many different methods are used to address users' opinions throughout the development process, from requirement gathering to product evaluation. Different methods can be used to involve users in the design. Traditional methods such as focus groups, brain storming and thinking aloud have recently been extended with new methods such as cultural probes, co-design, online crowdsourcing and living labs.

Focus group studies bring together a group of users to discuss a predefined theme. The focus group session is usually organized in an in-house laboratory. Through discussions among participants, researchers can capture subjective insights from user perspectives [17].

While minor adjustments may be tuned according to the aims of the studies, focus groups usually take place in lab settings. One of the main reasons focus groups are commonly used in user ideation and evaluation is that they allow researchers to hear users' direct opinions easily and, in a discussion setting, users have to ground their opinions. The presented ideas can also be further developed in the discussion. Focus 
group results can be very helpful when making design decisions and in convincing engineers/marketing experts.

To shift the control from the designers' hands to the users' ones, several experimental methods have populated the HCI research world. With cultural probes [18], designers are inspired by collections of users' open and often random ideas from diaries, pictures or collages. In co-design, the user role is an equal design partner which enables the designers and users make design decisions together.

The transformation of the decision-making process in innovation from the designers' own judgment to the users' mass opinions is currently bringing in the best practices in user-driven innovation. Many innovative companies today put their ideas in crowdsourcing media for evaluation and further development before starting to realize them. Web and social media provide good tools for this. The idea of online crowdsourcing or crowd-wisdom has become popular not only because the ideation process is free from geographical constraints but also because it provides promising results from an open and less scrutinized environment [19].

Open Web Lab (Owela) is an online space for open innovation with users, customers, developers and other stakeholders [20]. Owela utilises social media features for participatory design and open innovation. It is a place where users, researchers and companies can meet and discuss ideas and critique. Owela provides tools for understanding user needs and experiences and for designing new products and services together with users [20].

This kind of online forum in which users are free to discuss and ideate according to their own schedule attracts many wild ideas and is easily accessible to people around the world. A similar environment is OpenIDEO, launched by IDEO, a well-known design and innovation consultancy. The OpenIDEO online platform is targeted at creative thinkers and uses 'challenges' as a method to discuss and solve problems. OpenIDEO currently focuses on social innovations.

The limitation of focus group studies often comes from the fact that the data from users are collected out of the real context and they therefore plant risks of validity when innovation is released into its context: the real world [21]. Outside the actual usage environment, the focus group may not think about all the issues related to usage situations. Online innovation spaces may have the same limitation.

Taking design activities into real-world environments changes the environmental setting of the user studies in HCI research from laboratories to the real world, such as living labs. Living labs are defined by the European Network of Living Labs (ENoLL) as real-life test and experimentation environments where users and producers co-create innovations [22]. According to ENoLL, living labs employ four main activities: Co-Creation, Exploration, Experimentation and Evaluation.

While living labs focus on permanent user communities, innovation showrooms aim to provide environments for short-term co-creation and innovation activities in real-life environments. The Ihme showroom (Figure 4) is an open innovation and codesign space located in a shopping centre. In this showroom, visitors can see and try applications of new technologies for themselves and are invited to ideate on how the technologies could be utilised.

Even if user-driven innovation has been studied quite a bit, the methods are not yet established as practices. We wanted to study how different user-driven innovation methods can address users' perspectives. We selected and performed studies with 
three user-driven innovation methods to compare them in terms of ease of organizing the innovation activity, user motivation to participate and quality of the outcome of the innovation. As the methods were tailored to investigate user insights according to the specific innovation challenge (Open Telco Cloud services), it is possible for the identified differences of the three methods to be case-specific. The results still give insights into the pros and cons of these methods for future studies.

\section{Open Telco Case Study}

Open Application Programming Interface (API) standards are already widely used on the Internet, and Open APIs are the core components of several Internet services. Open Telco is an open API framework for mobile networks. It takes the data and functionalities traditionally possessed by teleoperators to the cloud. External service providers can access the data via the cloud [8]. This enables external development of mash-up services that take advantage of network assets, such as call and message control, mobile payment capability, user profile, location information or presence [8,22].

Mash-up services combine data and functionality from several external sources. A mash-up approach has proven successful on the Internet application market, and similar phenomena can be expected with Open Telco. Open Telco has great potential to increase innovation of new mobile services, as high volumes enable reasonable pricing for location information, and standardized Open APIs enable low costs and innovative application development. Even niche services can be provided to small user groups [8].

Operators possess a large amount of customer history data, such as location and call logs, which could be utilised to profile target users, e.g., for advertisements [23]. Open Telco APIs can even be used in conjunction. For instance, the user can receive a call or a message launched by the event that (s)he arrives at a certain location. These kinds of trigger services can also be initiated by the presence or close location of a friend or a group [23].

In the Open Telco case, our aim was to identify the usage possibilities with most potential as well as the initial user requirements for Open Telco APIs. We used scenarios to illustrate the possibilities. The scenarios also served as a common language between the users and the designers. Our aim was to study broadly the different possibilities of the Open Telco infrastructure and then identify the applications with most potential from both the users' and service providers' points of view.

The Open Telco scenario work started with initial descriptions of different service possibilities identified in an earlier activity. We wrote initial scenarios based on these descriptions. We held workshops with project partners in which we refined the scenarios and made sure that they illustrated the key new service possibilities of Open Telco. The project group included technical, business and user experience expertise. After the project group had agreed on the scenarios, we started the user-driven innovation activities in which we assessed the scenarios with the users and let them propose new usage possibilities. The following value proposals were selected as the starting points for the user-driven innovation activities: 
1. Universal user profile facilitates using the same profile for different services. This saves user efforts of updating separate profiles. The profile is always available via the cloud, even abroad.

2. Peer recommendations are received from the cloud. The recommendations can be selected based on the user profile and location, thus giving the user situationally relevant tips.

3. Call and location history can be collected in the cloud. The user can utilise the history data him/herself or the data can be used by service providers, for instance, to differentiate regular and occasional visitors.

4. Mobile ticket with integrated services is based on the possibility that the event organizer has contact with the ticket owners from the moment they buy the ticket. This facilitates different pre-during-after event services.

5. Reverse-charge messages and calls are based on the possibility that the user can ask the receiver to pay for a message or a call. This is useful in one-tomany messaging for instance.

6. Machine-to-machine communication services are based on a telecommunications facility embedded in different everyday objects.

7. Future TV could have many personal features similar to those of the Internet.

We illustrated value proposals 1-5 as PowerPoint clips with a main character named Matti to whom users could relate (Figure 1).

Different stories of Matti's life demonstrated what Open Telco value proposals could add to his life. Value proposals 6 and 7 were added as new value proposals after the workshop with the project team. With these value proposals, our aim was to generate user ideas for future TV services and user ideas for services based on machine-to-machine (M2M) communication. In the M2M and TV cases, our scenarios were very light as we just wanted to give the main idea to the users but did not want to turn their mindsets to a particular focus.

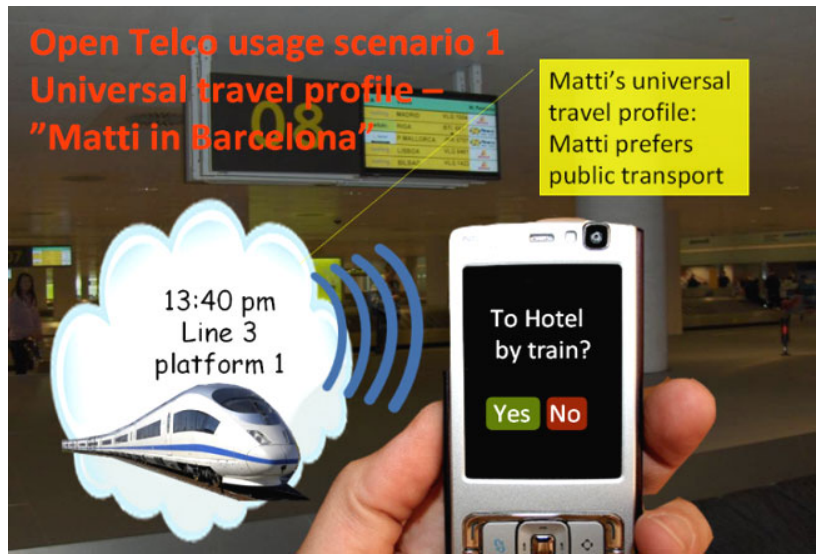

Fig. 1. An excerpt from a scenario illustration (universal travel profile) 


\section{Three User-Driven Innovation Methods in Practice}

The aim of our user-driven innovation activities was to ideate with users of Open Telco services based on the value proposals presented in the previous section. We selected three different user-driven innovation research methods: focus group, online crowdsourcing in the open web lab and direct interaction in the open innovation showroom. The following sub-sections describe the three studies in more detail.

\subsection{Focus Group Ideation}

The main aim of the focus group study was to obtain quick feedback from potential users on the proposed Open Telco service ideas. Another aim was to ideate with the participants on the newly introduced value proposals of future TV and Machine-tomachine communications. The study included two parts:

1. Illustrated scenarios of value proposal 4 (Mobile ticket, Figure 2) and value proposal 5 (Reverse-charge Multimedia Message, MMS) were presented to the participants. The researchers mediated discussions in which the participants gave feedback and ideas.

2. Value proposal 6 (Machine-to-machine communication, M2M) and value proposal 7 (Future TV) were presented to the participants by giving simple real-life examples. The participants were then asked to ideate in pairs on near future possibilities for Open Telco services.

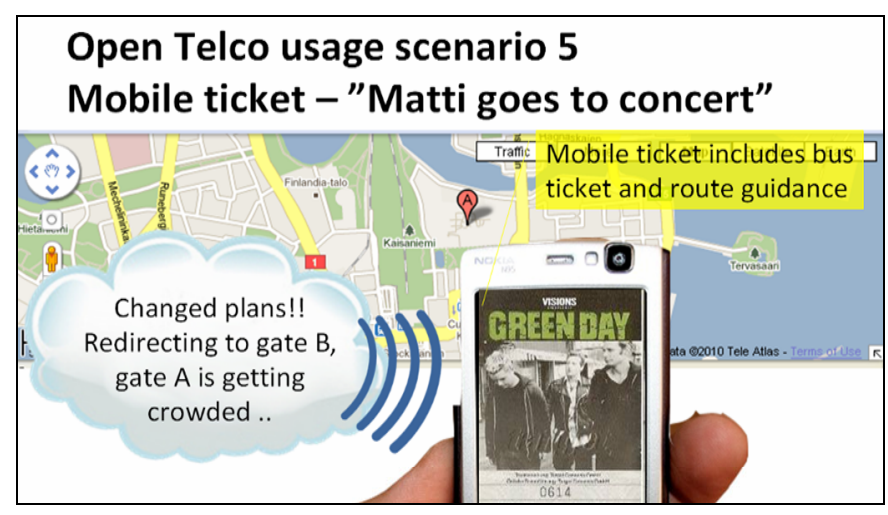

Fig. 2. Illustration of a mobile ticket scenario

Eight in-house scientists (four female and four male) who work in the area of ICT for Health participated in the focus group study. One researcher chaired the focus group and another observed and took notes. The scenario of value proposal 4 was presented to the participants with the PowerPoint illustrations. After the presentation, the following themes were discussed: 
- What did you like or dislike about the presented service?

- Can you suggest anything that could be added to the service?

- Could you foresee this service on the market? Would you recommend it to your friends? Why or why not?

After assessing the scenario of value proposal 4, the scenario of value proposal 5 was assessed in the same way.

After the two scenario evaluations, the participants were asked to ideate about future TV and machine-to-machine communication (M2M). The introduction to M2M ideation was as follows: 'Imagine everyday objects/machines like waste bins, cars and TVs talking to each other. Which ones would they be and how?' The participants were asked to discuss their ideas in pairs and to write the ideas down on post-it notes. After the ideation, each pair presented their favourite ideas and the ideas were discussed in the group.

The TV ideation followed the same procedure as the M2M did. As an example of future TV services, a Yahoo!-connected TV widgets demo was presented. The participants were asked: 'Imagine what else you could do on your TV. What other web-related functions would you like to have on your TV?'

The entire focus group session lasted one hour. The data collected included notes taken by the researchers and ideation post-its from the participants. The user feedback on the scenarios illustrating value proposal 4 (Mobile ticket) and value proposal 5 (Reverse-charge MMS) were satisfactory in terms of acceptance and novelty value. The ideations for value proposal 6 (Machine-to-machine communication) and value proposal 7 (Future TV) were short but fruitful. Several participants were excited about sharing their ideas by telling a full story. The researchers gained concrete ideas on how Open Telco services applied to future TV and how machine-to-machine communication could benefit users. The participants also gave ideas on how the proposed applications could be presented to attract users.

\subsection{Online Crowdsourcing in the Open Web Lab (Owela)}

The second study was carried out as online crowdsourcing in an open web lab (Owela). The ideation was based on the scenarios illustrating value proposals 1 (Universal user profile), 2 (Peer recommendations) and 3 (Call and location history). Another aim was to ideate usage possibilities for the new value proposals 6 (Machine-to-machine communication) and 7 (Future TV). The study included two parts:

1. Online users were briefed with texts and illustrated scenarios of value proposals 1,2 and 3 . This was followed by open discussions under different sectors of the Owela online forum, led by initial questions set up by the researchers. Participants could give feedback and ideas on the illustrated value proposals.

2. Value proposal 6 (Machine-to-machine communication) and value proposal 7 (Future TV) were illustrated by giving simple real-life examples with texts and images. Online users were free to use the 'add an idea' button as well as to comment on others' ideas and the initial ideas supplied by the researchers. 

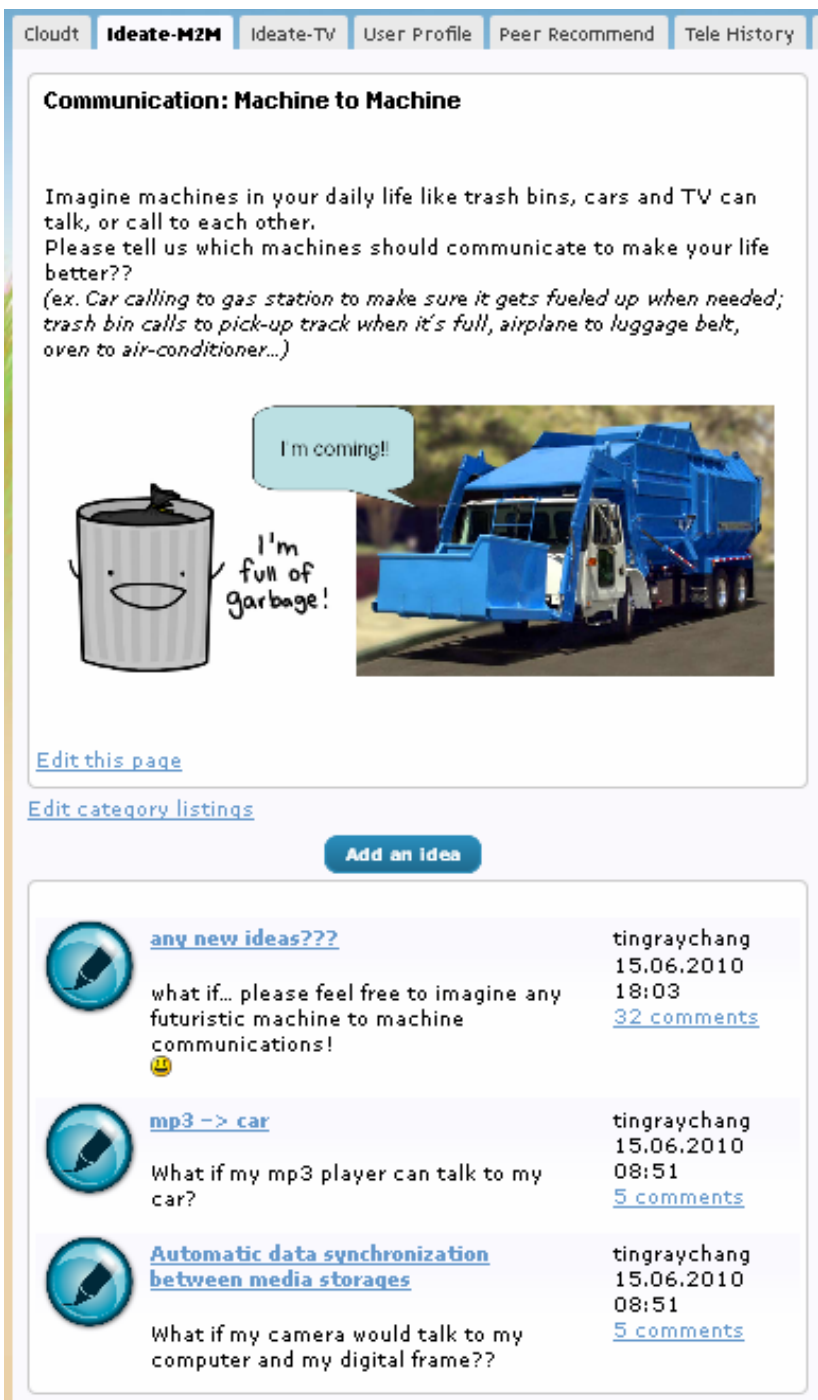

Fig. 3. Screenshot of the Owela online ideation page for machine-to-machine communication

The online studies lasted a month in total. During the first two weeks, new users were invited from university email newsletters, online international student groups and Facebook to discuss the first three value proposals. Forty-six new users joined Owela during the first two weeks to participate in our study. During the following two weeks, existing Owela users were also invited and the two new value proposals were added (Future TV and Machine-to-machine communication). The participants came from 11 countries in Europe, North America and Asia. All the users used English as the communication language. Owela online ideations and evaluations involved a total 
of 84 users. There were 48 males, 33 females and 3 unknowns. The ages of the participants ranged from 18 to 68 . Two researchers participated in moderating the discussions. The users had to register in the project discussion area to start. The users did not have to reveal their identities, but their online identities were displayed beside their comments. Many of the comments turned into discussions between the researchers and the users, and among the users.

The participants were briefed with an introduction page and were then able to proceed freely to the value proposals they wanted to see and comment on. Five tabs (Figure 3) took the users to the ideation pages where each value proposal was introduced using texts and illustrations, followed by questions from the researchers to encourage the users to leave comments and ideas. As an example, Figure 3 presents the ideation page for machine-to-machine communication.

During the ideation, the researchers stimulated the discussion with additional questions and comments. The overall Owela study produced a total of 221 user comments in a blog style, sectioned by topics with canonical orders. The results were analysed and the ideas grouped according to application areas and themes. Many innovative and wild ideas were produced as well as direct and passionate discussions on personal experiences and life stories. Some discussions ended with a general consensus on preferences of service ideas and acceptance. Other discussions ended with various directions of personal preferences, many with good reasons. The discussions illustrated the user ideas well and grounded the users' opinions. It was challenging to analyse the outcomes of the discussions systematically however.

\subsection{Direct Interaction at Ihme, the Open Innovation Showroom}

The main aim of the third study, direct interaction at an open innovation showroom (Ihme), was to present our ideas in a real-world setting and to interact directly with ordinary users as a new approach to user-driven innovation. The Ihme innovation showroom and co-creation space was located in a shopping centre (Figure 4). There were also other technology demonstrations such as a virtual travel experience and a 3D TV at the Ihme showroom. People who came to the Ihme showroom were free to have a look at any or all of the demos.

Similar to the Owela study, it was carried out with the scenarios illustrating value proposal 1 (Universal user profile), 2 (Peer recommendations) and 3 (Call and location history). The ideation process of value proposals 6 and 7 in this study was meant to be less structured and freer. The study was carried out in two parts:

1. The participants were briefed with illustrated scenarios of value proposals 1,2 and 3 . This was followed by an open discussion with the researcher and led by initial questions set up by the researcher.

2. Value proposals 6 and 7 (Machine-to-machine communication and Future TV) were illustrated as posters. Users were able to add their comments and ideas as post-it notes and study the notes left by other users. 


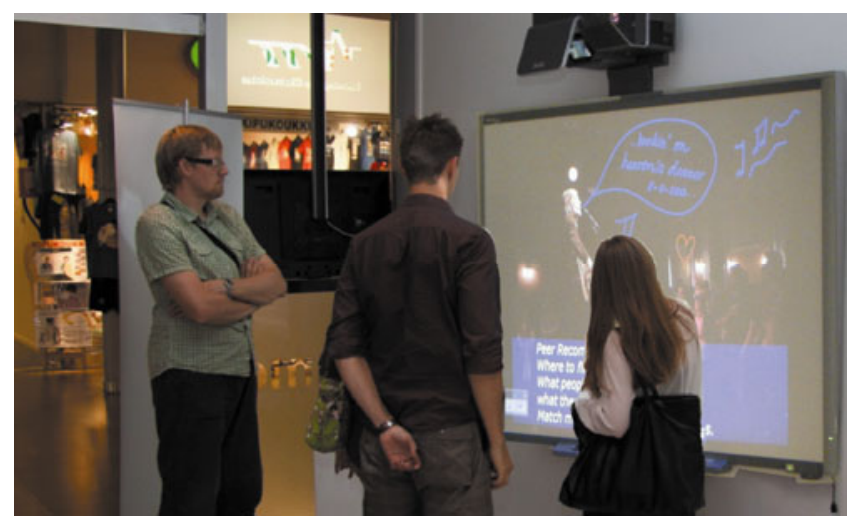

Fig. 4. Ihme innovation showroom

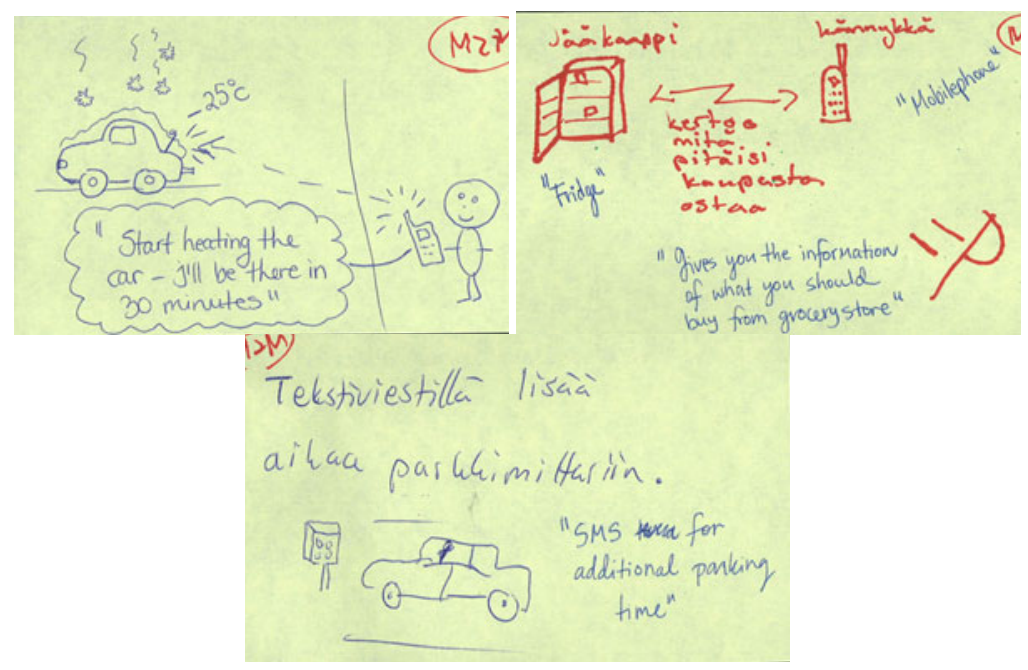

Fig. 5. Post-it notes from user ideations on machine-to-machine communication

The first period of the studies ran for nine days. The researchers invited ordinary people from the shopping centre to participate in the studies and interviewed a total of 26 people. As the interviews were conducted in an informal way, user demographics were not asked. Compared with the previous two studies, many of the participants in this study were less technology-oriented. The recruitment prioritized English, though Finnish researchers were also available. The participants were first briefed with a set of PowerPoint illustrations of the three first scenarios for a total of two to three minutes. Each participant was then interviewed by a researcher with a list of twelve predefined questions that covered personal preferences and acceptance of each value proposal, as well as ideas for additional services. The interviews were semi-structured 
and interactive. Many participants therefore used their personal experiences to express their opinions. The interviews lasted ten to twenty minutes.

The next period of this user study focused on the ideation of value proposals 6 and 7. Two posters illustrated the ideas. Users were invited to leave their ideas as post-it notes on the posters. The users could see others' comments and were able to comment freely, add a new idea or continue with the available ideas. For each comment, the participants received a lottery ticket to win cinema tickets. Each poster was displayed at the Ihme showroom for a week and the post-it notes were collected at the end of the week. Researchers were available so that users could discuss the ideas with them. In total, 13 post-it ideas were collected for the 'future TV' poster and 5 for the 'machineto-machine communication'.

Each ideation session with individual users lasted from 30 minutes to about 1 hour, depending on the interaction and discussion between the researcher and the participants. The data collected included notes taken by the researcher and ideation post-its from the participants. The user feedback on the scenarios of value proposals 1-3 was satisfactory in terms of acceptance and novelty value. Due to the semistructured discussion, the results were quantitative and structural. The ideations for value proposals 6 and 7 were not large in terms of quantity but interesting in terms of expressions. Figure 5 illustrates some of the post-its left by the participants.

It was challenging to tempt people who were passing by to participate in the study for a moderately long time. Many of the participants had come to the shopping centre with their families in their spare time. It turned out to be important to present the value proposals in such a way that ordinary, less technology-oriented users could quickly understand them. The flexibility of the schedule, according to each individual's available time, was also important. Direct interaction with users was fruitful and produced concrete ideas. In a real-world setting, the users were more interested in commenting on familiar topics such as future TV. Machine-to-machine communication was difficult to understand and several users commented that they did not need to know about it.

\section{Comparison of the Approaches}

An overview of the setups and results of the three user-driven innovation studies is presented in Table 1. The focus group is clearly a quick method that can be carried out in one or two hours, whereas Ihme and, especially, Owela usually require longer periods of time. An Ihme study could be carried out in one day, but the session for each participant would then have to be planned quite compact, and a good strategy to recruit users would be necessary. A focus group works well if the targeted user group is very specific, e.g., a certain work community. Owela is very useful for international studies as it overcomes the restrictions of time and place. Ihme is at its best when ordinary users are the target group. In the following sub-sections, we will analyse the differences in the methods with regard to the setup of the study, the user motivation to participate and the quality of the results. 
Table 1. Comparison of the three co-creation methods

\begin{tabular}{|c|c|c|c|}
\hline & Focus group & Owela & Ihme \\
\hline Length of the study & 1 hour & 1 month & 3 weeks \\
\hline Language & English & English & English/Finnish \\
\hline No. of users involved & $\begin{array}{l}8 \text { participants, } \\
4 \mathrm{~F}+4 \mathrm{M}\end{array}$ & $\begin{array}{c}84 \text { online users, } \\
49 \mathrm{M}+35 \mathrm{~F}\end{array}$ & 26 users \\
\hline Designer:user ratio & $2: 8$ & $2: 84$ & $1: 1$ \\
\hline Procedure & $\begin{array}{l}\text { Briefing } \rightarrow \text { Ideation } \\
\rightarrow \text { Discussion }\end{array}$ & $\begin{array}{c}\text { Briefing } \rightarrow \\
\text { Ideation+Discussion }\end{array}$ & $\begin{array}{c}\text { Briefing } \rightarrow \\
\text { Ideation+Discussion }\end{array}$ \\
\hline Study duration & 1 hour & 4 weeks & $\begin{array}{l}\text { 20 40 min per } \\
\text { user, } 3 \text { wks total }\end{array}$ \\
\hline Location & Finland & International & Finland \\
\hline Value proposals & $4(4,5$ and 6,7$)$ & $5(1,2,3$ and 6,7$)$ & $5(1,2,3$ and 6,7$)$ \\
\hline Environment & Laboratory & Real world & Real world \\
\hline Illustration material & $\begin{array}{l}\text { PowerPoint, video } \\
\text { clips of scenarios }\end{array}$ & $\begin{array}{l}\text { Screen shots of } \\
\text { scenarios }\end{array}$ & $\begin{array}{l}\text { PowerPoint, video } \\
\text { clips of scenarios }\end{array}$ \\
\hline Media & Face to face & Online & Face to face \\
\hline Data gathering & Notes and post-its & Online forum & $\begin{array}{l}\text { Interview notes } \\
\text { and post-its }\end{array}$ \\
\hline No. of comments & 63 & 221 & 252 \\
\hline Data from Scen. 1-3 & $\begin{array}{l}\text { Acceptance comments + } \\
5 \text { new* ideas }\end{array}$ & $\begin{array}{c}\text { Acceptance comments }+ \\
20 \text { new* ideas }\end{array}$ & $\begin{array}{l}\text { Questionnaire data } \\
\text { (19 questions) }\end{array}$ \\
\hline $\begin{array}{l}\text { Different categories } \\
\text { of ideas - future TV }\end{array}$ & 4 & 12 & 13 \\
\hline $\begin{array}{l}\text { Different categories } \\
\text { of ideas - M2M }\end{array}$ & 5 & 12 & 5 \\
\hline $\begin{array}{l}\text { Group/individual } \\
\text { discussions }\end{array}$ & Group & Group & Individual \\
\hline $\begin{array}{l}\text { User participation, } \\
\text { scheduled versus free }\end{array}$ & Scheduled & Free & Free \\
\hline
\end{tabular}

\subsection{Setting Up the Studies}

The illustration material for all three studies was a semi-automated PowerPoint slide show of scenarios in which the main character, Matti, was involved in stories that introduced different value proposals in everyday situations. The same material can basically be used with all three methods, with some subtle differences. In the Owela web lab, there is no possibility of oral introduction by the researcher. Therefore the illustrations of the proposed services must be very clear and easy to understand. The illustrations also have to be quite compact as the participants are not motivated to study long presentations. In Ihme, the material has to be designed to include elements that will tempt potential participants to come and have a closer look. The posters worked well for this purpose. In the focus group and Ihme, the slide shows worked, but for Owela the scenarios had to be shortened and, as the researchers were not always present, separate questions for each scenario had to be included. Effort was also made in the Owela study to ensure that the value proposal in the scenario was understandable without a human introducer.

In our case, the Owela and Ihme spaces with related human resources were already available. It was therefore quite easy to set up and perform the studies. The setting up of such research environments from scratch could involve an intensive workload. 


\subsection{Motivating Users}

The studies in the real-world environments, open web lab (Owela) and open innovation showroom (Ihme) attracted participants from more diverse backgrounds than the focus group as a laboratory setting to which participants were selected and invited for the session. The participants in Owela were found to be more technology oriented. Ihme in the shopping centre environment attracted more ordinary users.

In Owela, users were very motivated when they were interested in the topics. Some users revisited the site often to follow up new discussions. It is challenging, however, to raise the discussion if the topic is not interesting enough to the participants. Topics such as privacy issues or acceptance raised the most elaborate discussions. The Owela participants felt free to discuss how they felt without face-to-face confrontations. It can be concluded that a good Owela theme is one that raises feelings for or against.

In the focus group, the participants focused for a shorter period of time from understanding the theme to finishing the discussion. They may have been motivated but may not have had enough time to become inspired and ideate based on their reallife experiences.

In Ihme, the users' interests and focuses often depended on their schedule, as their visit to the shopping centre may have included prior plans and goals to achieve. The Ihme participation was not agreed in advance and the participants needed to be on a more flexible schedule to be involved. The ideation theme also has to be interesting to the participants and, in addition, some tempting elements should be presented to attract a closer look, e.g., an interesting illustration on a poster. Innovation showrooms are best suited to the ideation of tangible experiences with prototypes or simulated services. The Ihme innovation methods need to be developed to also allow short visits while still offering the users the possibility to participate.

The compensations for Ihme and Owela were based on a lottery whereas in the focus group, the compensation was just refreshments. With all three methods, small compensations were attractive ways to motivate participants.

\subsection{Data Quality}

The three qualitative studies produced many insights into the users in a 'thick descriptive way', which is more fruitful in such ideation activity than quantitative results. The three methods can also be compared quantitatively, as shown in Table 1. Ideation data are presented in terms of quantity (number of comments) as well as quality (different categories of ideas produced). In Ihme, the researcher discussed ideas with the participants and took notes at the same time instead of recording. This made note-taking quite challenging. Owela's online group discussions collected most user ideas both in terms of quantity and quality. Owela comments gave a wide and indepth range of user insights from daily experience sharing.

While all three studies produced rich, qualitative data, we found the data from the Ihme studies to be easily quantifiable, as the users' answers were documented following a set of questions and answered individually. Comparatively, it took more time and analysis to understand and summarize the data collected from Owela. The main difficulty was that the material was in discussion threads and the same user could have commented several times throughout the thread. 
Owela provided a platform that was free of time and space constrains for users to ideate and discuss. Ihme provided a co-creating space where researchers could really see and feel what users thought about cloud services (e.g., when a user took his phone and started acting out a scenario related to his idea). In the direct face-to-face interaction in Ihme and the focus group, we were able to understand the participants as individuals better than in Owela in which the participants were not present in person. In Ihme, the users were also given the chance to understand the technical possibilities by asking questions in direct interaction. In all three studies, the designers and researchers benefited from the various degrees of communication with the users. In the focus group, the researchers had investigator roles. In online crowdsourcing (Owela), the researchers mostly had observer roles and partly discussion partner roles. In the open innovation showroom (Ihme), the researchers had a more equal role to that of the users in a co-creating activity.

In the Owela web environment, the participants were almost anonymous (only an online identity was displayed beside the user's comment). Anonymity may have made the participants feel free to express themselves at their own pace and style. Consensus or influenced discussions may occur in Owela discussions (they did not happen in our study). It is then the researchers' duty to observe carefully or mediate the flow of discussion to stay on track. The permanent user community in Owela that was invited during the second round can be seen as a kind of lead user group. They had participated in different ideation activities and were more familiar with being involved in the discussions. The ideation diversity of our study was fruitful, possibly due to the mixture of lead and new users.

The comments and discussions in a focus group tend to carry a chance of redundancy. Our focus group participants sometimes commented easily by agreeing with previous speakers or were otherwise influenced by them.

In Ihme, each participant gave individual answers. Compared with the other two studies as group discussions, the comments were not influenced by other participants. From Ihme, it was therefore possible to report an overview of the participants' opinions in a quantitative way, e.g., 23 out of 26 are interested in trying cloud services. The ideations in Ihme may be less stimulated without continuous group discussions however. In the future, the Ihme method need to be developed so that they also facilitate the user-user dialogue and wider group discussions.

In the focus group, we had more short answers, such as 'yes I agree' and 'yes I agree with the previous comments', which did not provide in-depth information. In Owela we had large amounts of text in the comments, and some comments were actually life stories. Even if Owela comments were time-consuming to analyse, many useful insights came out of the data. In Ihme, the researchers were able to interact with the users, listen to the users' comments and then ask further questions straight away or discuss the proposed idea. In Ihme, the participants based their comments on thinking about situations in which they would use the service, as the following comments related to privacy show:

'It [peer recommendation services] feels like being tracked when you are on the road and everyone will make the same choices.'

'If it [universal profile] follows me everywhere, it is like a chip in my dog...' 
In Owela, the participants based their comments on both personal and general use, as the following comments show:

'There are going to be serious privacy issues though, so this would definitely need to be an opt-in service so people don't get upset.'

'I think I would be a bit worried about who gets access to my information and possible misuse issues.'

'It seems obvious to me that this information cannot possibly be kept private. It already bugs me that my car can be tracked as I cross bridges or toll points.'

In both Owela and the focus group, ideas were developed further in discussion. In Owela, however, the participants could comment and ideate according to their own schedule. In Owela the comments were often long and well analysed. Figure 6 illustrates an excerpt from an Owela ideation chain related to Future TV.

Participant (P) 1: 'TV scrapbook - what if I could copy and paste, e.g., recipes from a cooking show to my video cookbook (maintained in the cloud)?'

(con-)P 2 'I would love to get them on my mobile phone... would save me time at the store too if I could check for missing items in the recipe ...'

(con-)P 3: 'I would like my TV to collect a scrapbook from news and documents of topics I am interested in. For instance I save the word "environment" in its memory and it follows up all news and documents that deal with the environment and it collects a scrapbook on environment!'

(con-)P 4: 'Definitely a good idea! The semantic TV! I think as well as transmitting pictures, sound and subtitles, each frame/second/minute (whatever is practical) should have information that tells the TV/computer what the content in the picture means and potentially connects to other information. If something interesting appears in the picture, hit the Info button and the TV/computer gives a list of information relating to what is in the picture...'

Fig. 6. An excerpt from an Owela ideation chain on Future TV

With all three methods, we aimed to gain a firm idea of our users of the services by trying to understand the users' perspectives - 'walking a mile in the users' shoes'. With the development of user-driven innovation research methods, we are taken from observing from afar to a close-up understanding of our users. As a lesson learnt from collecting and analysing research data, user values and acceptances were easy and fruitful to discuss in the Owela online ideation. In the focus group, the users gave short answers that only provided a consensus that they were concerned about privacy issues in the scenarios related to the profile and call and location history. In Owela, the users were very comfortable discussing their personal experiences openly and providing solutions that made them feel more secure. In Owela, it is also possible to see how many people have similar or different opinions in the group discussions but not in a consensus way to produce only one conclusion. In Ihme, the researchers and users discussed issues in a side-by-side way and shared experiences.

If the data from the three studies were to be labelled in some way, it would be: the focus group was the most efficient way of producing quick ideas; Owela produced the most creative ideas; and Ihme produced the ideas that are closest to real-life (tangible) experiences. 


\section{Conclusions}

Focus group studies have been one of the best established user research methods in the HCI field. The focus groups are also well-suited to user-driven innovation. A well-defined service proposal can receive quick feedback in a focus group within a short time. Based on our studies, there are also other alternatives for focus groups depending on the targeted users and results.

Online crowdsourcing is a good method for reaching a large, international group of users. Registered Owela participants can be utilised as a lead user group as they are a kind of ideation professional. In the web environments, the users felt free to talk about their personal experiences, such as dislikes and fears. Personal preferences and issues such as privacy and ethics could be discussed thoroughly and the outcome could be very well grounded. Innovation by the crowd is a powerful method in which ideas can be fomented. The ideation theme has to be interesting enough to motivate the users to participate and continue their participation however. The ideation theme has to be such that it can be understood quickly without excess documentation. Online discussion material may be hard to analyse afterwards as the material is in different discussion threads. If quantitative data are needed, separate voting activities can be organized during the discussion.

The co-creation of tangible experiences, services and products could benefit most from demonstrations in an open innovation showroom such as Ihme. In Ihme, the ideation theme has to be such that it tempts passers-by to have a closer look. As in Ihme, the sessions were not scheduled beforehand and the schedule could become a challenge. Ideally, each user should be able to devote as much (or as little) time to the ideation as (s)he happens to have. This will require new methods for Ihme studies. The Ihme innovation showroom facilitated direct user-designer interaction in the actual usage context. As suggested by earlier studies, this dialogue can be very powerful as it not only foments ideas but also makes the designer understand the user's world. In our study, users only exchanged and commented on ideas by other users in the latter part of the study with post-it notes on the idea poster. Methods that would facilitate wider communication with other users are a future need for Ihme.

Acknowledgement. Our research was carried out as a part of Tivit, the Strategic Centre for Science, Technology and Innovation in the Field of ICT (www.tivit.fi), the Cloud Software Program (www.cloudsoftwareprogram.org). The work is partly funded by Tekes (the Finnish Funding Agency for Technology and Innovation, www.tekes.fi). We would like to thank our research partners in the Cloud Program, especially TeliaSonera and Aalto University with whom the Open Telco research was carried out. We would also like to thank our colleagues at VTT who assisted with the Owela and Ihme studies. We are most grateful to all the users who contributed in the co-creation activities.

\section{References}

[1] Kanstrup, A.M., Christiansen, E.: Selecting and evoking innovators: Combining democracy and creativity. In: Proceedings of the 4th Nordic Conference on Humancomputer Interaction: Changing Roles (2006) 
[2] Holmquist, L.: User-driven innovation in the future applications lab. In: Conference on Human Factors in Computing Systems (2004)

[3] Botero, A., Vihavainen, S., Karhu, K.: From closed to open to what? An exploration on community innovation principles. In: MindTrek 2009, Tampere (2009)

[4] Khurana, A., Rosenthal, S.R.: Towards holistic 'front-end' in new product development. The Journal of Product Innovation Management 15(1), 57-74 (1998)

[5] Alam, I.: Removing the fuzziness from the fuzzy front-end of service innovations through customer interactions. Industrial Marketing Management 35, 468-480 (2006)

[6] Armbrust, M., Fox, A., Griffith, R., Joseph, A.D., Katz, R., Konwinski, A., Stoica, I.: A view of cloud computing. Communications of the ACM 53(4), 50-58 (2010)

[7] Miller, M.: Cloud computing: Web-based applications that change the way you work and collaborate online. Que Publishing Company (2008)

[8] Suikkola, V.: Open exposure of telco capabilities - identification of critical success factors for location-based services in Open Telco. In: 6th International Conference Wireless and Mobile Communications (ICWMC), pp. 202-208 (2010)

[9] Verganti, R.: Design, meanings, and radical innovation: A metamodel and a research agenda. Journal of Product Innovation Management 25(5), 436-456 (2008)

[10] Grönroos, C.: Service management and marketing: A customer relationship management approach. John Wiley \& Sons Inc., Chichester (2000)

[11] Muller, M.J., Kuhn, S.: Participatory design. Communications of the ACM 36(6), 24-28 (1993)

[12] Hyvönen, K., Heiskanen, E., Repo, P., Saastamoinen, M.: Kuluttajat tuotekehittäjinä: Haasteita ja mahdollisuuksia (Consumers as product developers: challenges and possibilities). In: Kuluttajat kehittäjinä, pp. 31-48. Kuluttajatutkimuslaitos, Helsinki (2007)

[13] Sandstrom, S., Magnusson, P., Kristensson, P.: Increased understanding of service experiences through involving users in service development. European Journal of Innovation Management 12(2), 243-256 (2009)

[14] Von Hippel, E.: Lead users: A source of novel product concepts. Management Science 32(7), 791-805 (1986)

[15] Heiskanen, E., Hyvönen, K., Repo, P., Saastamoinen, M.: Käyttäjät tuotekehittäjinä (Users as product developers). Teknologiakatsaus 216. Tekes (2007)

[16] Antikainen, M., Vaataja, H.: Rewarding in open innovation communities - how to motivate members. International Journal of Entrepreneurship and Innovation Management 11(4), 440-456 (2010)

[17] Nielsen, J.: Usability Engineering. Academic Press, Boston (1993)

[18] Gaver, B., Dunne, T., Pacenti, T.: Culture Probes. Interactions 6(1), 21-29 (1999)

[19] DeVun, L.: Looking at how crowds produce and present art. Wired News, November 19 (2009),

http: / /www.wired.com/techbiz/media/news / 2007 / 07 /crowd_captai $n$ ? currentPage=all

[20] Näkki, P., Antikainen, M., Virtanen, T.: Participatory design in an open web laboratory owela'. In: Proc.CHI 2008. ACM, New York (2008)

[21] Genise, P.: Usability Evaluation: Methods and Techniques. Version 2.0. University of Texas (2002)

[22] European Network of Living Labs, http: / /www. openlivinglabs . eu/

[23] Raivio, Y., Luukkainen, S., Juntunen, A.: Open Telco: A new business potential. In: Proceedings of the 6th International Conference on Mobile Technology, Application \& Systems, pp. 1-6 